\title{
Internal Pair-Merge: the Missing Mode of Movement*
}

\author{
Marc Richards \\ University of Leipzig. Institute of Linguistics \\ Beethovenstr. 15, 04107 Leipzig. Germany \\ richards@uni-leipzig.de
}

\begin{abstract}
In this brief article, I point out the predicted existence of a second mode of movement (alongside Internal Set-Merge) that should be sanctioned under Chomsky's Strong Minimalist Thesis, namely Internal Pair-Merge, essentially yielding 'movement by adjunction'. I then suggest one possible area in which the computational system makes use of this mode of movement - namely, it allows us to implement Agree-less Move to phase heads (aka 'pure EPP-movement', or Chomsky's (2007, 2008) Edge-Feature movement) without compromising the Activity Condition, thus potentially yielding a truly minimalist, narrow-syntactic analysis of optional, 'discourse-driven', 'stylistic' movement operations like topicalization and focus-movement. Not only does Internal Pair-Merge emerge as a theoretical possibility implied by the SMT (section 1), but it is also a device that is fully exploited by the computational system (section 2).
\end{abstract}

Key words: Merge, Internal Merge, Set-Merge, Pair-Merge; optional movement, EPP, Edge Feature; Activity Condition; Strong Minimalist Thesis.

\section{Table of Contents}

1. What emerges from Merge?

2. IPM as Agree-less Move
3. Conclusions

References

\section{What emerges from Merge?}

As first discussed within a minimalist context in Chomsky 1995 (henceforth MP), an operation that forms larger units out of those already constructed is conceptually necessary for any recursive system of hierarchic discrete infinity. This operation, which Chomsky dubs Merge, can in that sense be said to "come for free"; its initial formulation is given in (1).

* I would like to thank the audience at the 5th GLOW in Asia conference, held at Jawaharlal Nehru University (New Delhi) in October 2005, for their stimulating comments and questions on this material, as well as an anonymous reviewer for helpful suggestions. 


\section{(1) $\operatorname{Merge}(\alpha, \beta) \rightarrow \mathrm{K}=\{\mathrm{H}(\mathrm{K}),\{\alpha, \beta\}\}$}

This states that merger of two syntactic objects creates an unordered set, $\mathrm{K}$, of those two items, and that one of the two members is privileged in the sense that it provides the label for the larger object $\mathrm{K}$ thus created, the label being a head. Given Merge, the operation Move is recast as Merge of a copy (of which various interpretations have been offered in the subsequent literature, including remerge, multidominance, and copy-plus-deletion algorithms). As such, the earlier distinction between substitution and adjunction as fundamentally different operations, fundamental to GB theories of movement, largely disappears - all we have is Merge. Instead, the (presumably real) distinction between specifiers/complements and adjuncts is captured via the label, as in (2).

(2) a. 'Substitution' (projection, formation of "a new category" [MP:248])

$\operatorname{Merge}(\alpha, \mathrm{K}) \rightarrow \mathrm{L}=\{\mathrm{H}(\mathrm{K}),\{\alpha, \mathrm{K}\}\}$

b. 'Adjunction' (formation of a multi-segment category)

$\operatorname{Merge}(\alpha, \mathrm{K}) \rightarrow \mathrm{L}=\{<\mathrm{H}(\mathrm{K}), \mathrm{H}(\mathrm{K})\rangle,\{\alpha, \mathrm{K}\}\}$

Only in (2a), substitution, is the label identical to the head of K; in the case of (2b), adjunction, the label is an ordered pair. As a technical consequence of this view of XP-adjunction as forming a multi-segment category, YP adjoined to XP is excluded from the checking domain of $\mathrm{X}$, and thus cannot be subject to Last Resort (since feature-checking cannot be at stake in its triggering). Therefore, Chomsky (MP:324ff.) suggests that XP-adjunction might be relegated to a postsyntactic "stylistic" component instead of forming part of the computation of LF (i.e. narrow syntax). In short, the existence of syntactic XP-adjunction is rejected (though see Kidwai 2000 for discussion and an alternative view which reconciles XP-adjunction with the morphosyntax), and the phenomena described in terms of XP-adjunction (such as scrambling, topicalization, extraposition, right-node raising, etc.) belong to PF or some such external or interface component. In this way, the optionality and semantic vacuity of these operations can be kept apart from core syntactic feature-driven movement, such as Move-DP (Case-driven A-movement), Movewh (A-bar operator movement) and the like.

The picture changes again, however, in Chomsky 2000 (henceforth MI), in which a basic, structural, syntactic difference is revived between substitution and adjunction, now reconceived as Set-Merge (SM) and Pair-Merge (PM), respectively. Whereas SM is a symmetrical operation creating a binary unordered set, PM is asymmetric, its output an ordered pair:

a. Set-Merge ('substitution')

$\operatorname{Merge}(\alpha, \beta) \rightarrow\{\alpha, \beta\} \quad=$ 'symmetric'

b. Pair-Merge ('adjunction')

$\operatorname{Merge}(\alpha, \beta) \rightarrow<\alpha, \beta>\quad=$ 'asymmetric' $(\alpha$ adjoins to $\beta)$ 
As further elaborated in Chomsky 2004 (henceforth BEA), PM is required in order to accommodate adjuncts (nonargument modifiers) into the structure, yielding predicate composition in the semantic component, SEM. If the need to express this relation is imposed by the interface with SEM, then this requirement has the status of an interface condition; any minimal device that affords its satisfaction can then be said to follow from (or at least conform to) the Strong Minimalist Thesis, SMT (see BEA, Chomsky 2007, Chomsky 2008, for discussion of this point). In that sense, both SM and PM are compatible with the SMT. However, (XP-)adjunction, as a distinct structure-building movement operation, remains excluded, as things stand.

Alongside the Set vs. Pair dimension of Merge, there is a more fundamental distinction in the manner in which Merge may apply. Up through Chomsky 2001 (henceforth $\mathrm{DbP}$ ), Move is regarded as an 'imperfection', something beyond the conceptually necessary, as its absence from other symbolic systems would seem to confirm. That is, Move seems unique to human language and, as such, would appear to be an "unexplained property of UG" in the sense of Chomsky 2008. In BEA, however, Chomsky offers a reconceptualization of Move that removes this conceptual hurdle. Now reconceived as Internal Merge (IM), Move is simply one of the two logical possibilities for merger of $\alpha$ and $\beta$ : either $\alpha$ (merged to $\beta$ ) is separate from $\beta$, or else $\alpha$ is a subpart of $\beta$ :

(4) Two logical possiblities for $\operatorname{Merge}(\alpha, \beta) \rightarrow\{\alpha, \beta\}$

a. Subcase 1: $\alpha$ is distinct from/outside of $\beta \rightarrow$ External Merge (EM)

b. Subcase 2: $\alpha$ is part of/contained inside $\beta \rightarrow$ Internal Merge (IM)

In the latter case, we have an operation, IM, which yields the displacement property. Movement, qua internal merge, is thus an entailment of the SMT: it would have to be stipulated not to exist (and any such stipulation would be a departure from SMT), as asserted by Chomsky in the following quote:

(5) “[D]isplacement is not an 'imperfection' of language; its absence would be an imperfection." (BEA: 8)

As a result of this shift in perspective, both (4a)/EM and (4b)/IM come equally free, as summed up in (6).

(6) EM and IM both conform to SMT.

We have therefore arrived at a system in which Merge comes in three 'types', each with distinct interpretive properties at SEM (each thus meeting a distinct interface need). Firstly, there is EM, yielding argument structure ("deep"/"base" semantics); then there is IM, yielding discourse/information structure and scope/binding relations (what Chomsky terms "surface" or "edge" semantics); then, finally, there is PM, yielding adjuncts (predicate modification and composition). The former 
two (EM vs. IM) stand in an opposition that corresponds to argument vs. discourse structure - the "duality of semantics" that Chomsky views as a requirement of SEM (Chomsky MI, BEA, 2008). If IM is free, then it is expected (under SMT) that the language system will make use of the free device to implement and satisfy this interface need (rather than innovating any new or special devices). Standing apart from these is PM: whereas EM and IM create unordered sets (cf. (4)), PM creates ordered pairs.

However, as set out in (7), there is a striking asymmetry in this system, and an unexpected one if EM and IM really are just a single operation (Merge). The set/pair dichotomy applies only to the external dimension of Merge. Thus only three of the four logical possibilities implied by the two dimensions Set vs. Pair and External vs. Internal are part of the current theory:

\begin{tabular}{|l|c|c|}
\hline & Set-Merge & Pair-Merge \\
\hline External & EM & PM \\
\hline Internal & IM & \\
\hline
\end{tabular}

Unless we make stipulations to the contrary, the combination of the SM-PM and EM-IM dimensions of Merge should actually yield a symmetrical typology under SMT. That is, IM should also be split along the set/pair dimension so that, in addition to two kinds of EM, there are also two kinds of IM (movement) implied by the system.

(8)

\begin{tabular}{|l|c|c|}
\hline & Set-Merge & Pair-Merge \\
\hline External & ESM & EPM \\
\hline Internal & ISM & IPM \\
\hline
\end{tabular}

A fourth formal possibility thus also 'comes free', namely Internal Pair-Merge (IPM).

(9) ESM, ISM, EPM and IPM all conform to SMT.

1. What IPM is not, then, is $\mathrm{I}(\mathrm{S}) \mathrm{M}$ of a pair-merged unit. The latter is discussed in BEA (pp.15-18) in the context of a cyclic implementation of anti-reconstruction effects with adjuncts (Freidin/Lebeaux effects):

(i) $\left[_{w h}\right.$ Which $\left.<\left[_{\beta} \text { picture of Bill }\right]_{\mathrm{i}}\right]\left[_{\alpha}\right.$ that $\mathrm{John}_{\mathrm{j}}$ liked $\left.]>\right]$ did he $\mathrm{j}_{\mathrm{j} / *_{\mathrm{i}}}$ buy $t_{\mathrm{wh}}$

In (i), the adjunct/modifier relative clause that Bill liked is pair-merged cyclically in the base position of the $w h$-phrase, creating a PM unit $\langle\alpha, \beta\rangle$ that is then $w h$-moved in the usual way (i.e. ISM) to spec-CP. The lack of reconstruction follows on the assumption that $\alpha$ (containing John) adjoined to $\beta$ is "on a separate plane" (i.e. not part of the "simple", set-merged structure), so that he can only c-command $\beta$ and not $\alpha$ - thus $\alpha$ in the lower copy of $<\alpha, \beta>$ is 'invisible' for the 
The predicted existence of this fourth mode of Merge - that is, Merge that yields the ordered pair $\left\langle\alpha, \beta>\right.$ wherein $\alpha$ adjoined to $\beta$ is part of $\beta^{1}-$ seems to have gone unnoticed in the literature, but there is nothing in the current theory that rules it out (technically or conceptually - see section 2.3 ). With this main point made, the question that arises is empirical - does the system actually make use of this formal option? I would like to suggest that it does, and indeed quite extensively. Let us therefore briefly consider how IPM might be expected to work, what its properties might be, and thus what kinds of phenomena we might usefully describe in terms of this new formal mechanism.

\section{IPM as Agree-less Move}

The first possibility that suggests itself as perhaps the most obvious potential application of IPM is that it might provide us with a minimalist reworking of syntactic XP-adjunction, with which the parallels are clear - both, essentially, implement move-by-adjunction. That is, XP-adjunction, qua IPM, now emerges from Merge as a natural, necessary component of narrow syntax, contra the concerns raised by Chomsky in MP (see previous section). Since IPM is simply PM applied internally, we might expect it to share with PM the property of applying completely freely (cf. MI:134). As such, IPM would seem to provide just the analytical tool we need in order to accommodate within narrow syntax the kind of truly optional, 'discourse-driven' movement operations previously analysed in terms of (X/XP-)adjunction and/or relegated to PF (the 'stylistic component'). As noted in the previous section, these might include topicalization (10a), long-distance (A-bar) scrambling (10b), and focus-movement (10c); all three share the property of being semantically vacuous in the sense that they are 'undone' at SEM/LF, undergoing radical reconstruction and thus failing to feed binding. (Other possibilities for optional and/or vacuous adjunction-type movements that may be analysed in terms of IPM include head movement, cf. DbP:37ff., and successive-cyclic, 'escape-hatch' movement, cf. the Edge Feature (EF) movement to phase edges of Chomsky 2008. See also section 2.3 below and footnote 11 for more on EF-movement and the EF-IPM connection.)

purposes of binding/reconstruction (though see Chametzky 2003:206 for criticism of the reasoning behind this). Whether we accept this anti-reconstruction story or not, the point to be made here is that the movement operation in (i) is not IPM; rather, it is ISM of an EPM object. IPM means that the derived copy/position, not the base copy/position, is created by PM. 
(10) 'Semantically vacuous' optional movement [a = English; $\mathrm{b}=$ Japanese; $\mathrm{c}=$ Dutch $]$

a. (i) Herself Mary $_{\mathrm{i}}$ has always liked $\mathrm{t}_{\mathrm{i}}$

(ii) $*$ Mary $_{\mathrm{i}}$, herself $\mathrm{f}_{\mathrm{i}}$ has always liked $\mathrm{t}_{\mathrm{i}}$

(Thráinsson 2001:176)

b. (i) Nani- $o_{\mathrm{i}}$ John-ga [Mary-ga $e_{\mathrm{i}}$ katta ka] sitteiru ${ }^{2}$ what- ${ }_{\mathrm{ACC}} \mathrm{John}_{\mathrm{NOM}}$ Mary-$_{\text {NOM }}$ bought Q knows

'John knows what Mary bought.' $\quad$ (Bošković \& Takahashi 1998:353)

(ii) $[\text { Hotondo-no uta-o }]_{\mathrm{i}}$ dareka-ga saiwaini $\mathrm{t}_{\mathrm{i}}$ utatta most- $_{\text {GEN }}$ song- ${ }_{\text {ACC }}$ someone- ${ }_{\text {NOM }}$ fortunately sang

'Someone fortunately sang most of the songs.' some >> most, *most >> some

(Miyagawa 2003:188)

(iii)* Karera- $\mathrm{o}_{\mathrm{i}}$ [otagai-no sensei-ga [Hanako-ga $\mathrm{t}_{\mathrm{i}}$ hihansita them- ${ }_{\text {ACC }}$ each.other- ${ }_{\text {GEN }}$ teacher- ${ }_{\text {NOM }}$ Hanako-$_{\text {NOM }}$ criticized to] itta]

that said

*'Each other's teachers said that Hanako criticized them.'

(Kitahara 2002:179)

c. ...dat [zo'n foto van haarzelf $\left.]_{j}\right]_{j}$ zelfs Jan deze actrice ${ }_{i}$ niet graag $t_{j}$ that such picture of herself even Jan this actress not gladly toont

shows

(Neeleman 1994:399)

IPM, like its XP-adjunction predecessor, would thus be a 'costless' operation unconstrained by Last Resort (LR), hence truly optional and semantically inert (see, amongst many others, Saito 1989, Fukui 1993, Saito \& Fukui 1998, Takano 1998 on the LR-evading nature of XP-adjunction).

Nevertheless, such true optionality sits uneasily with current minimalist principles of interface economy, such that we might want to think twice before allowing IPM to apply in the absence of a local, featural trigger (i.e. in violation of LR). For one thing, the movements in (10) are not, in fact, entirely semantically vacuous. Whilst it may be true that they do not affect logico-semantic interpretation (binding, reference, truth and the like), they clearly do have an effect on discourse structure (that is, the information packaging of the structure into theme/rheme, topic/focus, new/old, etc.). It is therefore arguable that there is no such thing as truly optional, vacuous movement: all 'optional' movement has some effect on interpretation at the interface, whether it be the scope/binding or the discourse/informational kind

2. Radical reconstruction is observed here in that the wh-phrase nani-o can only be interpreted as taking scope over the interrogative, embedded clause (Bošković \& Takahashi 1998:353). 
of 'edge semantics'. Since the operations in (10) yield interpretive outcomes at SEM, they do in fact conform to minimalist notions of interface economy, the logic of which is informally defined in (11), and are thus amenable to description in terms of LR after all. (See DbP:34, BEA:10, Reinhart 1995, Fox 2000 on interface economy, and Kidwai 2000, Bailyn 2001, 2003, Miyagawa 1997, 2003 on the point that no truly optional movement exists and that all movement conforms to LR, affecting interpretive outcomes).

\section{(11) Interface economy}

All movement must be triggered (= Last Resort); all triggered movement is obligatory (only the trigger may be optional); this trigger must be cashed out in terms of extra effects at SEM (= Full Interpretation: 'no superfluous symbols').

Within the Probe-Goal-Agree incarnation of checking theory (MI et seq.), there is just a single formal trigger for movement. This is the EPP-feature, construed as an extra requirement of the probe. Agree, yielding valuation of a probe's features, may thus take place without concomitant Move insofar as the EPP-feature is optional (thus checking and agreement are no longer contingent on movement). In line with (11), optional EPP-features are motivated insofar as they have an effect on outcome (DbP: (60)), be it scopal or informational or both. New discourse interpretations such as those arising in (10) are thus the effect (function), and not the cause (triggering mechanism), of movement in this system, allowing us to dispense with 'greedy', pseudo-semantic features of the topic/focus kind.

The upshot, then, is that even IPM can and must be triggered, namely by an (optional) EPP-feature, like any other instance of movement. As such, the interface economy principles of Last Resort and Full Interpretation apply to IPM and ISM alike. It may well be that the movements in (10) involve IPM; however, we cannot define IPM and distinguish it from ISM on the basis of triggers, since both ISM and IPM must be triggered and there is, we assume, only one type of trigger: the EPP-feature. What, then, is the defining property of IPM that allows us to tell it apart from ISM?

The claim I would like to make is that what yields the IPM/ISM distinction is not the (presence/type of) trigger, but rather the presence/absence of Agree. That is, whereas IM of the Set-Merge kind (ISM) always involves a component of Agree (cf. MI, DbP), IPM is Agree-less (or 'pure-EPP') movement of the kind that has been brought to light by a number of authors in recent years (see below). This claim is summarized in (12).

\section{(12) a. Move fed by Agree = ISM}

b. Move independent of Agree $=$ IPM

The notion that movement must be parasitic on Agree in the Probe-Goal system is bound up in the Activity Condition on Agree, the requirement that both probe 
and goal be active (visible) for Agree by virtue of unvalued (uninterpretable) features. Probes just are unvalued ( $\phi$-)features, whereas goals (interpretable ( $\phi$-)sets) must be rendered visible for Agree by means of activation features (Case, for the $\phi$-system). In this way, the Activity Condition (AC) captures, directly, the idea that Case and $\phi$-agreement are two sides of the same coin (cf. Schütze 1997:126, Martin 1999:16, Boeckx 2003, Rezac 2004:Chapter V, and many others) - you cannot value one without valuing the other. This yields 'Inverse Case Filter' effects, i.e. derivations that crash due to the probe going fatally unvalued when the goal has already been Case-valued (and thus is no longer active for a second application of Agree):

(13) a. * It seems [ $t$ was told Mary [that Bill is a liar]]

b. * A lot of people seem [ $t$ are intelligent]

c. * There seem [that a lot of people are intelligent]

d. * There seems to a strange man [that it is raining outside]

As (13c-d) show, these effects occur irrespective of movement, obtaining equally with 'pure' (long-distance) Agree, and so cannot be reduced to the EPP requirement. Therefore, the fact that movement fails in (13a-b) can be taken to follow from the failure of Agree (as in (13c-d)); that is, movement is impossible without prior agreement.

In MI and BEA, Chomsky suggests that the Agree component of Move (where Move is a composite operation comprising Agree + Piedpipe + (Re)Merge) serves to identify the goal which Move then shifts to satisfy the EPP-feature on the probe. Move, in short, comprises and is parasitic on Agree:

\section{(14) Move $\rightarrow$ Agree}

At least until the revised system of Chomsky 2008, we therefore have a system in which Agree can take place without Move (yielding long-distance agreement effects such as those which obtain in expletive-associate existentials, e.g. There appears to be a man in the garden) whereas the reverse is not true. Not least, this view that 'Move implies Agree' (i.e. (14)) captures a basic but nontrivial fact about movement: namely, that whatever moves to spec-Probe is, for the most part, the same category with which the probe agrees (and not some other random XP) thus nominative subjects raise to spec-TP, accusative objects raise to spec- $v \mathrm{P}(\mathrm{Object}$ Shift), and $w h$-phrases raise to interrogative spec-CP, etc. It follows that, for the implication in (14) to hold, EPP-features cannot be independent, probing features in their own right; rather, they are simply movement 'diacritics' associated with ( $\phi$-)probes (cf. Roberts \& Roussou 2003).

However, there is a major problem confronting this view of the Move-Agree relation (a problem to which IPM, I propose below, offers a simple and effective solution). As pointed out by Nevins \& Anand (2003), there is plenty of crosslin- 
guistic evidence that Agree and EPP-satisfaction (movement) are doubly dissociated in many languages. That is, not only can Agree take place without movement, but movement must also be allowed to take place in the absence of Agree. Thus, as numerous authors have observed in recent years, languages such as Russian, Japanese and Hindi exhibit structures in which a previously Case-valued argument raises to a $v$ P-external A-position (assumed to be spec-TP) despite the fact that such an argument should be inactive for Agree (and thus raising) as a consequence of lacking an unvalued Case feature (see Bailyn 2003, Lavine \& Freidin 2002 on Russian; Miyagawa 2001, 2003, 2004, 2005 on Japanese; Nevins \& Anand 2003 on Hindi). The data set in (15-17), for example, illustrates that the satisfaction of T's EPP-feature need not involve an agreed-with nominative argument.

(15) Russian (Generalized Inversion - Bailyn 2003; adversity impersonals - Lavine \& Freidin 2002)

a. Soldata ranilo pulej soldier- $_{\text {ACC }}$ wounded- ${ }_{3 \text { PNS }}{ }^{3}$ bullet- $_{\text {INSTR }}$

'A soldier was wounded by a bullet.'

b. (i) Milicionerov ${ }_{i}$ ranilo puljami prinadležaščimi drug militiamen- $_{\text {ACC }}$ wounded- ${ }_{3 \text { PNS }}$ bullets- ${ }_{\text {INSTR }}$ belonging each drugu $_{\mathrm{i}}$ other- ${ }^{-}$DAT

(ii) *Puljami prinadležaščimi drug drugu ranilo $_{i}$ bullets- ${ }_{\text {INSTR }}$ belonging each other- ${ }_{\text {DAT }}$ wounded- ${ }_{\text {3PNS }}$ milicionerov $_{\mathrm{i}}$ militiamen- ${ }_{\text {ACC }}$ 'Militiamen were wounded by each other's bullets.'

(L\&F 2002:280(42))

3. $3 \mathrm{PNS}=3 \mathrm{rd}$ person neuter singular ('default' agreement). 
(16) Japanese (Miyagawa 2001, 2003, 2004, 2005; Kitahara 2002)

a. [Hotondo-no uta-o] $]_{\mathrm{i}}$ dareka-ga $\mathrm{t}_{\mathrm{i}}$ utatta most- $_{\text {GEN }}$ song- ${ }_{\text {ACC }}$ someone- ${ }_{\text {NOM }}$ sang 'Someone sang most of the songs.' some $>>$ most, most $>>$ some

(Miyagawa 2003:188)

b. (?) Karera- $\mathrm{o}_{\mathrm{i}} \quad$ [otagai-no sensei]-ga $\mathrm{t}_{\mathrm{i}}$ hihansita $^{4}$ them-ACC each other-GEN teacher-NOM criticized *'Each other's teachers criticized them.' (Kitahara 2002:167)

c. 'Focus agreement' (Miyagawa 2004, 2005):

(i) Taro-ga nani-o kai-mo sina-kat-ta Taro- $_{\text {NOM }}$ what- $_{\text {ACC }}$ buy-MO do- ${ }_{\text {NEG-Past }}$

(ii) *Nani-o ${ }_{i}$ Taroo-ga $\mathrm{t}_{\mathrm{i}}$ kai-mo sina-kat-ta ${ }^{5}$ ${ }^{\text {what- }}{ }_{\text {ACC }}$ Taro- ${ }_{\text {NOM }}$ buy-MO do- ${ }_{\text {NEG-Past }}$ 'Taro didn't buy anything (at all).'

(17) Hindi (Nevins \& Anand 2003)

kisii šaayer-ne har ghazal $\operatorname{lik}^{h}{ }_{\mathrm{ii}}$

some poet- ${ }_{\text {ERG }}$ every song ${ }_{\text {NOM }}$ write- $_{\text {f.PERF }}$ (some >> every; *every >> some)

'Some poet wrote every song.'

(Nevins \& Anand 2003: 370)

The structures in (15)-(17) share two key properties. Firstly, they all involve A-movement, i.e. standard raising-to-subject (spec-TP) as in English, as attested by the fact that these movements feed scope/binding and have no effect on focus/discourse structure (they are felicitous in 'out-of-the-blue', 'what happened?' contexts); cf. Lavine \& Freidin 2002:270ff, Bailyn 2003:176 (note 8). Secondly, they all lack morphological ( $\phi$-)agreement, indicating an absence of Agree between $\mathrm{T}$ and the raised DP. Indeed, Agree(T, DP) is barred in all of these examples due to failure to meet the Activity Condition, as follows.

In Russian (15), the previously Case-valued accusative argument raises to specTP despite the fact that it should be inactive for Agree with T (and thus raising) as a consequence of having already been valued (to accusative) by $v$. In Hindi (17), the ergative DP is similarly inactive for Agree with T, assuming ergative either to be lexical/inherent (as in Nevins \& Anand 2003) or to be assigned by $v$ (cf. Müller 2004) and thus lacking an unvalued structural Case feature; further, if $\mathrm{T}$ values nomina-

4. This sentence is judged acceptable, unlike the similar binding attempt in (10biii). The lack of reconstruction in all the 'pure-EPP' (Agree-less) A-movements in (15)-(17) is captured under Nevins \& Anand's (2003) PEPPER principle (roughly, Pure EPP Excludes Reconstruction) - see their paper for discussion.

5. This example illustrates a lack of reconstruction in that the indeterminate reading of the $w h$-item nani is only possible in scope of -mo particle (see Miyagawa 2004, 2005). 
tive on the unraised object, $\mathrm{T}$ too should be inactive and thus unable to initiate further probing, thus the AC is again violated here. Finally, in Japanese (16), T has already agreed with the subject, valuing the $(\phi-)$ probe on $T$ and nominative on the DP. Not only should the accusative DP be inactive for the movement-feeding Agree(T, DP) operation, as in (15), but $T$ should itself be inactive for a second instance of Agree (and thus raising), as in (17). ${ }^{6}$ Again, these structures should not be possible if the movements in question are subject to the AC.

Clearly, the strong position that Move implies Agree (cf. (14)) cannot be maintained: If Agree is subject to the AC, then raising to spec-TP in (15)-(17) cannot involve Agree and must therefore be instances of Move without Agree. There is little question, then, that we have to accommodate Agree-less movement into the computational system. ${ }^{7}$ The question is how best to do this. Ideally, we want to achieve the necessary weakening of (14) ('Move implies Agree') without excluding the familiar kind of movement that is parasitic on Probe-Goal Agree and that is associated with morphological agreement (cf. (13)). That is, we have to reconcile (15)-(17) with the AC.

There are two main approaches to achieving this aim in the literature. The first is to weaken the $\mathrm{AC}$ so that inactive elements are visible to probes for certain operations (specifically, for Match, a subcomponent of Agree). The second is to abandon the AC altogether, so that items remain permanently available for Move/Agree (there is thus no active-inactive distinction). Both approaches are problematic. Let us briefly consider each of these possibilities in turn, before suggesting IPM as a less problematic alternative in section 2.3.

\subsection{Match-driven Move (Kitahara 2002, Boeckx 2003)}

According to the first approach, the $\mathrm{AC}$ is a condition only on Agree (i.e. valuation). Probe-Goal can still occur without resultant Agree/valuation whenever the AC doesn't hold: this is simply Match. Match alone is then claimed to be sufficient for feeding Move.

6. The Japanese derivation sketched here follows the analysis in Kitahara 2002. Alternatively, Miyagawa 2004, 2005 proposes 'focus agreement' in topic-prominent languages like Japanese, so that T has a Focus probe instead of a $\phi$ /Agree probe in such languages.

7. As a reviewer notes, this is a long-standing observation, going back at least to Belletti \& Rizzi's (1988) analysis of Romance psych-verb construcions, in which non-nominative experiencers raise to the canonical subject position (spec-TP, in our terms) despite a lack of agreement with the finite verb (which agrees with the internal argument). These and other plausible cases of Agree-less movement to the subject position, such as locative inversion and certain impersonal constructions, may well provide additional instances of IPM. It is worth clarifying, in this connection, that my claim here is not that Agree-less movement is a previously unnoticed phenomenon in the literature (the 'missing mode of movement' of the title); rather, I am claiming that such movements are plausibly characterized as instantiations of a previously unnoted ('missing') formal possibility, namely IPM. That is, I am claiming only to have identified the formal mechanism behind these movements. This mechanism then allows Agree-less movement to be naturally accommodated within the minimalist architecture, something which has so far proven problematic (for the reasons given in the following subsections). 
Match-driven Move is thus premised on a fundamental distinction between Match and Agree. This is the same distinction that underlies Chomsky's (MI:123) notion of defective intervention (DI), as defined in (18): it is precisely on the assumption that inactive DPs are visible to probes for Match (but not for Agree) that we expect unvalued features to intervene for Agree without themselves being a potential goal for Agree (i.e. without themselves being able to value the probe in question), yielding DI effects.

(18) Defective intervention (MI:123 (42), 129; DbP; Chomsky 2008; Rezac 2004; Hiraiwa 2005)

In structure $\alpha>\beta>\gamma$, where $>$ is c-command and $\beta$ and $\gamma$ both match probe $\alpha$, inactive $\beta$ blocks matching (and thus Agree) between $\alpha$ and $\gamma$.

Insofar as DI is a real phenomenon, we have independent empirical evidence for the Match-Agree distinction and thus for the weakening of the AC that this approach to (15)-(17) entails. In fact, Chomsky offers just three empirical arguments for DI: it yields superraising and (certain) MLC effects (cf MI:128-9 (47)); it yields the lack of long-distance nominative agreement across in-situ quirky subjects in Icelandic (cf. MI:130-1 (51)); and it provides an empirical argument for the claim that $\mathrm{T}$ (unlike $\mathrm{C}$ and $v^{*}$ ) is not a phase head (see BEA:21-2, Chomsky 2008: 152 for details). The validity of the Match/Agree distinction thus hinges on just these three cases. However, as discussed in Richards 2008, all three have simpler, arguably more plausible explanations (in particular the Phase Impenetrability Condition, PIC). For reasons of space, I will not reproduce the relevant counterarguments here; instead, let us focus on a possible conceptual argument for DI. It could be argued, to this end, that Probe-Goal should apply freely (cf. BEA:13), and that only (valued) $\phi$-sets should matter to $\phi$-probes (that is, Case features should be irrelevant); see Rezac 2004 for such an argument. If correct, then intervention by inactive $\phi$-sets (i.e. Match/DI) is the null assumption: it could only be excluded by stipulation.

Alternatively, however, we could just as well argue against DI on conceptual grounds. Ideally, either a feature is visible as a potential goal (i.e. it is active) or it is not; any further distinctions (such as 'visible for Match but not for Agree/Value', 'visible for Match and Move but not for Agree/Value', both of which are invoked in Chomsky's three empirical cases mentioned above) are surely then a departure from optimality and the SMT. On such a view, only active elements should be visible to probes and thus act as interveners; this, in turn, enables the AC and Case features to do the job they were originally designed to do. After all, if active and inactive DPs alike are visible to probes, then why would the system have Case/activation features (and the AC) in the first place? Why not dispense with them altogether (as in Nevins 2004)? From the minimalist perspective, there seems to be no reason for rendering DPs active, via Case features, if they are visible anyway; therefore, if DI is real, then Case is a departure from the SMT, serving no purpose from the perspective of the interfaces. Recall from above that such a rationale for Case/AC is, in fact, offered by Chomsky (see DbP (4:(2c)), BEA (14:(10ii))) - Case serves to identify and determine goals, ensuring convergence by rendering goals visible to 
probes (which could not otherwise be valued, violating Full Interpretation). However, it is precisely this rationale that Match/DI weakens - goals (interpretable $\phi$-sets) are visible to probes anyway, whether they have unvalued Case features or not. Match/DI thus deprives us of a conceptually necessary role for Case.

Such a role for Case can only be maintained if, instead of DI, the null assumption is actually as in (19), which elevates the AC to the status of an interface condition.

\section{(19) Feature visibility (syntax) / 'Strong Activity Condition'}

Only unvalued features are visible to the syntax (Probe-Goal etc.)

The tenability of (19) is of course open to empirical scrutiny. From the conceptual perspective, however, it allows for a fully lookahead-free syntax that operates exclusively on uninterpretable (unvalued) formal features, as seems desirable if the syntax can neither know nor care about matters of (LF-)interpretability. Interpretable/valued feature sets should, on such grounds, be invisible to the syntax, indistinguishable from pure semantic and phonological features and therefore equally irrelevant to the syntactic computation - this is arguably the null assumption that (19) captures. If (19) indeed holds, then it now follows that Agree is impossible unless we have a feature that renders interpretable $\phi$-sets visible to the syntax. Such a feature (Case) now simply follows from the SMT, and specifically from the need to ensure that Full Interpretation is met (at SEM); goal-activeness is thereby deduced.

As stated above, this line of reasoning is denied if we assume DI and the Match/Agree distinction. Case and the AC only make sense if there is no DI/Match, i.e. if (19) holds. If we accept this line of argumentation, then (15)-(17) cannot be analysed as Match-driven Move.

\subsection{Pure-EPP movement (Nevins 2004; also Lavine \& Freidin 2002,}

Nevins \& Anand 2003, Chomsky 2005)

Another possibility is to dispense with the AC and/or Case altogether (rather than with Match/DI). Pursuing this strategy, Nevins (2004) argues that the movements in (15)-(17) obtain purely for the EPP-feature (i.e. they do not involve Agree and the valuation of uninterpretable features), and that the existence of such pure EPPmovement denies the $\mathrm{AC}$, which he defines as follows:

(20) Activity Condition (version in Nevins 2004)

Inactive elements are not accessible for further operations

[Nevins 2004:9 (29)]

Crucially, for Nevins, "further operations" encompasses Move as well as Agree. Thus (20) bars movement of inactive elements, rendering this version of the AC logically incompatible with pure EPP-movement. It thus follows that the activity condition in the form of (20) cannot hold and must be eliminated. 
Whilst this is an interesting and carefully reasoned conclusion, and whilst Nevins's proposal that the movements in question (cf. (15)-(17)) are purely EPPdriven is surely the correct one, I would contest the other premise on which the argument is based, namely (20). As we saw in our discussion of (13), the AC for Chomsky is a condition only on Agree, not on Move (it thereby captures the CaseAgreement connection). Only derivatively does the AC constrain Move, insofar as Move is parasitic on Agree (i.e. insofar as (14) holds). Since the AC applies only to Agree, the existence of pure EPP-movement of inactive elements is logically incompatible only with (14) (i.e. the claim that Move implies Agree); it is not, however, incompatible with the AC per se (defined as a condition on probes and goals, i.e. on Agree). All that follows is that pure EPP-movement cannot involve Agree (thus the AC holds vacuously in these cases), which is exactly the desired result given the lack of Agree(ment) in (15)-(17), as discussed above. Therefore, only the version of the AC in (20) must be rejected; there is no need to eliminate or reject the AC on Agree.

Indeed, the desired conclusion that pure EPP-movement cannot involve Agree (contra (14)) only follows if we maintain the AC on Agree. That is, the lack of morphological agreement with the movements in (15)-(17) is unexpected if the $\mathrm{AC}$ is renounced. This is because syntactic elements would remain, in effect, permanently active and thus able to enter into multiple, indeed unlimited, Agree operations. As we saw in (13), Inverse Case Filter effects attest that this cannot be correct. ${ }^{8}$ The key property of pure EPP-movement, namely that it is Agree-less movement, is exactly what the AC in fact predicts and ensures.

In sum, we do not need (or want) to abandon the $\mathrm{AC}$ in order to allow for pure EPP-driven movement. Such an abandonment would only be necessary if movement of inactive elements did involve Agree(ment). Since it doesn't (cf. (15)-(17)), pure EPP-movement tells us nothing about the AC as a condition on Agree.

\subsection{A third possibility: IPM}

The movement phenomena in (15)-(17) show us that we have to allow for Move without Agree. That is, pure EPP-movement is an inescapable empirical fact. Numerous questions remain, however, as to whether and how pure EPP-movement can be implemented in the grammar in a manner conforming to the SMT. Clearly, the EPP-feature cannot operate as a probe in such constructions. If inactive elements are invisible to probes (i.e. if we renounce DI and maintain (19)/AC, as proposed above), then EPP-probes cannot exist, precisely because they do not seek

8. Other mechanisms can be invoked to reinstate ICF effects in an AC-less system. Thus Nevins postulates a "Single Case Constraint" to the effect that "a DP that is valued with more than one case feature is illegible to PF". However, this only captures one half of the AC, as probes, too, cannot be fully valued more than once under the AC (hence 'Case Filter' effects, e.g. *It seems John to be happy). Further, the very existence of Case features in the first place remains something extra (i.e. unexplained from the SMT perspective) without (19), and the latter cannot be maintained on the AC-less approach. 
active goals (contra the Activity Condition on Probe-Goal relations); therefore, Agree-free movement cannot involve Probe-Goal Agree. ${ }^{9}$ What, then, is the formal relation between EPP-features and the inactive elements that move to satisfy them in $(10) /(15)-(17)$ ?

It seems clear that this relation cannot be one of Set-Merge (SM). If only active heads can project, and SM implies projection of the probe/head (cf. (2a)), then pure EPP-movement (which involves inactive heads) cannot involve Set-Merge. Yet movement, as currently conceived (cf. internal merge in (7)), is Set-Merge. This would seem to exclude Agree-free movement from the theory. The challenge, then, is to come up with a formally precise mechanism that allows Agree-free movement in a principled and restrictive manner. I would like to submit that, once we recognize that the internal/external dimension should apply to Pair-Merge as well as to Set-Merge (i.e. the symmetrical typology in (8)), exactly such a mechanism emerges: IPM.

Firstly, IPM does not involve projection of the head (cf. (2b): XP-adjunction creates a multi-segment category rather than a change of category). Inactive heads - those that lack Agree probes, as manifested by default agreement in Russian (15), or whose probe is already valued, such as the adjunction sites in (10) - may thus freely undergo IPM to satisfy EPP-features. Further, since only inactive items may undergo IPM, it follows that IPM must occur after ISM (i.e. after Agree-driven movement), implying an intrinsic ordering between the two merge types. ${ }^{10}$

IPM thus allows Agree-free and Agree-constrained movement to harmoniously co-exist, as desired:
a. IM with Agree ([+ projection])
$=\mathrm{ISM}$
... optionally followed by...

\section{b. IM without Agree ([- projection] $) \quad=$ IPM}

In short, we can have our cake and eat it: IPM allows us to abandon the idea that Agree is involved in (15)-(17) (hence the lack of morphological agreement) without weakening or abandoning the AC (and with it the simplest explanation of Case Filter and Inverse Case Filter effects in terms of activation features, and the SMT-conforming rationale for the latter in terms of (19)).

There is at least one further useful application of IPM as Agree-less Move worth mentioning here, and that is that it offers a means of describing (and imple-

9. This 'probe' would be unique in a further respect, namely in being able to be satisfied/valued via EM (i.e. via Merge of an expletive) rather than via Agree(/IM). This expletive-related anomaly is a familiar and long-standing problem that has appeared in many guises throughout the development of minimalist checking theory; see, e.g., MP:311-2 for the strong-feature precursor.

10. This is, of course, in line with earlier analyses of the relation between A-movement, A-bar movement and interpretation, in which binding theory was taken to apply after the former but before the latter (hence the reconstruction property of A-bar movement) - see, for one version of this, the 'NP-structure' of Williams 1994. 
menting) successive-cyclic movement through phase edges under the PIC. Such movements are notoriously problematic in terms of Probe-Goal Agree: not only do they involve lookahead to avoid crash of goal/activation-features at the lower phase level (cf. Chomsky 2008, Franks 2005 and others), but there is simply no evidence for Agree at the relevant intermediate stages (cf. Boeckx 2003, Boškovič 2004). Again, these problems are solved in a maximally simple way if no Agree is involved at the intermediate phase-levels, i.e. if this is just another case of movement purely for EPP (viz. IPM). ${ }^{11}$

We conclude, then, that Agree-less, pure-EPP movement is Internal Pair-Merge.

\section{Conclusions}

A (re)consideration of the status of Merge in current minimalist theorizing has led to the following straightforward conclusions. (i) Movement, qua Internal Merge, does not have to be Set-Merge; it can also be Pair-Merge - that is, Internal Pair-Merge is predicted to exist. (ii) IPM (we have argued) is best regarded as characterizing Agree-less movement (i.e. pure EPP-movement), a kind of movement long recognized in the literature; this coexists with movement fed by Agree, which is constrained by the Activity Condition - that is, Internal Set-Merge. (iii) IPM is fully exploited by the computational system, offering a simple and transparent analysis of a wide range of phenomena, including: pure EPP-movement of inactive elements in Russian, Hindi and Japanese; 'vacuous' A-bar operations such as topicalization and long-distance scrambling; successive-cyclic movement through intermediate phase edges; and, plausibly (though not explored here), an alternative Agree-free approach to topic/focus-prominence (cf. Miyagawa's (2004, 2005) "focus-agreement"; see footnote 6) - and maybe also

11. Chomsky 2008 (p. 151), too, suggests that we solve the problem of intermediate phase-edge movement by treating such movement as driven by the Edge Feature (EF) of the phase head rather than by Agree. This raises the question of to what extent IPM, as proposed here, differs from EF-movement as proposed by Chomsky in that paper. There are several substantive differences, though the two are by no means incompatible. Firstly, EF (for Chomsky) is a movement trigger (akin to the EPP-feature of previous works), yielding A-bar positions, rather than a type of movement per se. IPM may well, therefore, equate with that kind of movement that is triggered by EF, without redundancy (it is a nontrivial claim that EF triggers IPM rather than ISM). On the other hand, EF-movement and IPM do not denote the same operations: the former, for Chomsky, yields A-bar movement to the phase edge (thus contrasting with Agree-driven movement to phase-internal positions, which is A-movement), yet IPM clearly instantiates both A- (cf. (15)-(17)) and A-bar (cf. (10)) types of movement. The A-IPM cases in (15)-(17), then, would be unlikely candidates for EFmovement in Chomsky's system; further, there are cases of A-bar movement that might be better analysed as involving probe-driven, Agree-type movement (such as matrix wh-movement; see Rizzi 2006 on "criterial freezing": essentially (in our terms) AC applied to the A-bar system), and which would therefore be ISM on the analysis presented here but (presumably) EF-movement for Chomsky. In short, there is both (i) IPM that corresponds to Agree- and not to EF-movement, and (ii) EF-movement that corresponds to ISM and not to IPM. (It is worth noting, tangentially, that Chomsky 2007 proposes that EF is unerasable, hence the availability of multiple specifiers. If so, then it is not even clear that EF is sufficient any longer as a movement trigger, since movement does not result in feature deletion here. I leave this issue for consideration in future work.) 
(for future research) head movement, locative inversion, experiencer raising (cf. footnote 7), Icelandic stylistic fronting (Dennis Ott, p.c.), and so forth. (iv) IPM is optional, insofar as its trigger (EPP-feature) is optional. (v) IPM can potentially bring under the fold of 'optimal design' many of the robust, pervasive phenomena that have previously been analysed in terms of optional XP-adjunction but which have so far eluded minimalist analysis on grounds of the AC, interface economy and Last Resort.

In sum, XP-adjunction in the form of IPM as a second mode of syntactic movement would, to borrow Chomsky's refrain, have to be stipulated not to exist.

\section{References}

Bailyn, John (2001). “On Scrambling: A Reply to Boškovič \& Takahashi”. Linguistic Inquiry 32: 635-658.

Bailyn, John. (2003). "Does Russian Scrambling Exist?” In: Karimi, S. (ed.). Word Order and Scrambling. Oxford: Blackwell, pp. 156-176.

Belletti, Adriana; Rizzi, Luigi (1988). "Psych-verbs and Theta Theory". Natural Language and Linguistic Theory 6: 291-352.

Boeckx, Cedric (2003). Islands and Chains: Resumption as Stranding. Amsterdam: Benjamins.

Boškovič, Željko. (2004). "On the Locality of Move and Agree: Eliminating the Activation Condition, Generalized EPP, Inverse Case Filter, and PhaseImpenetrability Condition." University of Connecticut, manuscript.

Boškovič, Željko; Takahashi, Daiko (1998). "Scrambling and Last Resort". Linguistic Inquiry 29: 347-366.

Chametzky, Robert (2003). "Phrase Structure”. In: Hendrick, R. (ed.) Minimalist Syntax. Oxford: Blackwell, pp. 192-225.

Chomsky, Noam (1995). The Minimalist Program. Cambridge, Mass: MIT Press.

Chomsky, Noam (2000). "Minimalist Inquiries: the Framework". In: Martin, R.; Michaels,

D.; Uriagereka, J. (eds). Step by step. Cambridge, Mass.: MIT Press, pp. 89-156.

Chomsky, Noam (2001). "Derivation by Phase". In: Kenstowicz, M. (ed.). Ken Hale: A Life in Language. Cambridge, Mass.: MIT Press, pp. 1-52.

Chomsky, Noam (2004). "Beyond Explanatory Adequacy". In: Belletti, A. (ed.). Structures and Beyond. The Cartography of Syntactic Structures (volume 3). Oxford: Oxford University Press.

Chomsky, Noam (2007). "Approaching UG from below". In: Interfaces + Recursion = Language? Chomsky minimalism and the view from Syntax-semantics, V. Sauerland and H-M. Gärtner (eds.), Berlin: Mouton de Gruyter, pp. 1-30.

Chomsky, Noam (2008). "On Phases". In: Foundational Issues in Linguistic Theory. Essay in Honor of Jean-Roger Vergnaud, C. Otero et al. (eds.), Cambridge, Mass: MIT Press, pp. 134-166.

Fox, Daniel (2000) Economy and Semantic Interpretation. Cambridge, Mass: MIT Press. Franks, Steven (2005). "Agnostic Movement". Abstract for poster presented at NELS 36. Fukui, Naoki (1993). "Parameters and Optionality". Linguistic Inquiry 24: 399-420. Hiraiwa, Ken (2005). Dimensions of Symmetry in Syntax: Agreement and Clausal Architecture. MIT, doctoral dissertation. 
Kidwai, Ayesha (2000). XP-Adjunction in Universal Grammar. Scrambling and Binding in Hindi-Urdu. Oxford/New York: Oxford University Press.

Kitahara, Hisatsugu (2002). "Scrambling, Case, and Interpretability". In: Epstein, S. D.; Seely, T. D. (eds.). Derivation and Explanation in the Minimalist Program. Oxford: Blackwell, pp. 167-183.

Lavine, James S.; Freidin, Robert (2002). "The Subject of Defective T(ense) in Slavic". Journal of Slavic Linguistics 10: 253-289.

Martin, Roger (1999). "Case, the Extended Projection Principle, and Minimalism". In: Epstein, S. D.; Hornstein, N. (eds.). Working Minimalism. Cambridge, Mass: MIT Press, pp. 1-25.

Miyagawa, Shigeru (1997). “Against Optional Scrambling”. Linguistic Inquiry 28: 1-25. Miyagawa, Shigeru (2001). "The EPP, Scrambling, and Wh-in-Situ”. In: Kenstowicz, M. (ed.). Ken Hale: A Life in Language. Cambridge, Mass.: MIT Press, pp. 293-338. Miyagawa, Shigeru (2003). "A-Movement Scrambling and Options without Optionality”. In: Karimi, S. (ed.). Word Order and Scrambling. Oxford: Blackwell, pp. 177-200.

Miyagawa, Shigeru (2004). "On the EPP”. In: McGinnis, M. \& Richards, N. (eds.). Proceedings of the EPP/Phase Workshop (MITWPL).

Miyagawa, Shigeru (2005). "Unifying Agreement and Agreement-less Languages”. In Proceedings of WAFL2 (MITWPL).

Müller, Gereon (2004). "Argument Encoding and the Order of Elementary Operations". University of Leipzig, manuscript.

Neeleman, Ad. (1994). "Scrambling as a D-structure phenomenon". In: Corver, N.; van Riemsdijk, H. (eds.). Studies in Scrambling: Movement and Non-Movement Approaches to Free Word-Order Phenomena. Berlin: de Gruyter, pp. 387-429.

Nevins, Andrew (2004). "Derivations without the Activity Condition". In: McGinnis, M.; Richards, N. (eds.). Proceedings of the EPP/Phase Workshop (MITWPL).

Nevins, Andrew; Anand, Pranav (2003). "Some AGREEment Matters". In: Garding, G.; Tsujimura, M. (eds.). WCCFL 22 Procedings. Somerville: Cascadilla, pp. 370-383. Reinhart, Tanya (1995). "Interface Strategies". OTS Working Papers in Linguistics. Utrecht.

Rezac, Milan (2004). Elements of Cyclic Syntax: Agree and Merge. University of Toronto, doctoral dissertation.

Richards, Marc (2008). “Quirky Expletives”. In: d'Alessandro, R.; Hrafnbjargarson, G.; Fischer, S. (eds) Agreement Restrictions. Berlin: Mouton de Gruyter, pp. 181-213. Rizzi, Luigi (2006). "On the Form of Chains: Criterial Positions and ECP Effects". In: Cheng, L.; Corver, N. (eds.). Wh-Movement: Moving On. Cambridge, Mass: MIT Press.

Roberts, Ian; Roussou, Anna (2003). Syntactic Change. A Minimalist Approach to Grammaticalization. Cambridge: Cambridge University Press.

Saito, Mamoru (1989). "Scrambling as semantically vacuous A'-movement". In: Baltin, M.; Kroch, A. (eds.). Alternative Conceptions of Phrase Structure. Chicago: University of Chicago Press, pp. 182-200.

Saito, Mamoru; Fukui, Naoki (1998). "Order in Phrase Structure and Movement". Linguistic Inquiry 29: 439-474.

Schütze, Carson (1997). INFL in child and adult language: Agreement, Case, and Licensing. MIT, doctoral dissertation. 
Takano, Yuji (1998). "Object Shift and Scrambling”. Natural Language and Linguistic Theory 16: 817-889.

Thráinsson, Höskuldur (2001). "Object Shift and Scrambling”. In: Baltin, M.; Collins, C. (eds.). The Handbook of Contemporary Syntactic Theory. Oxford: Blackwell, pp. 148-202.

Williams, Edwin (1994). Thematic Structure in Syntax. Cambridge, Mass: MIT Press. 